\title{
Perceived Competence as a Mediator in Parental Engagement in Speech Therapy
}

\author{
Nurfariha Mdshah*, Zainal Madon and Nellie Ismail \\ Department of Human Development and Family Studies, Faculty of Human Ecology, Universiti Putra Malaysia, \\ 43400 UPM Serdang, Selangor, Malaysia
}

\begin{abstract}
Parental engagement has been recognised as a critical factor in providing optimal speech therapy services to children. However, it continues to be challenging for clinicians to effectively engage parents in speech and language intervention for their children. Therefore, this study was conducted to investigate the roles of parental expectation and parent-therapist communication on parental engagement in speech therapy and to determine the contribution of the parent's perceived competence as a mediator. A total of 389 respondents were selected from government hospitals in Malaysia for this cross-sectional study. Four instruments were administered: Parental Expectation Scale, Therapist-Parent Communication Questionnaire, Perceived Competence Scale, and Parent Home-programme Compliance Questionnaire. In addition, descriptive, bivariate, and mediation analyses were performed using SPSS and Smart-PLS software to address the study objectives. The results showed that perceived competence partially mediated the relationship between communication and expectation on parental engagement. Thus, it can be concluded that to ensure parental engagement in a

ARTICLE INFO

Article history:

Received: 28 March 2021

Accepted: 6 July 2021

Published: 21 September 2021

DOI: https://doi.org/10.47836/pjssh.29.3.15

E-mail addresses:

rihashah@gmail.com (Nurfariha Mdshah)

zainalm@upm.edu.my (Zainal Madon)

nellie@upm.edu.my (Nellie Ismail)

*Corresponding author

child's intervention which is vital for a better outcome. Parents need to be competent and believe strongly in their capabilities to practise in speech and language intervention. Moreover, policymakers and clinicians should focus on strategies that can improve parental expectations and communication.

Keywords: Competence, parental engagement, speech and language disorder, speech therapy
\end{abstract}




\section{INTRODUCTION}

The involvement of family members, especially parents, is one of the key principles upheld by many professional speech-language pathology associations (American Speech-Language-Hearing Association, 2008). Parental involvement is considered the best practice in children's early intervention (Division for Early Childhood, 2014). The amount of practice received by children can be increased by involving and engaging parents in the intervention so that the relevant speech and language activities can be implemented with their children at home (Sugden et al., 2019). Furthermore, parents involvement in their children's intervention can maintain the targeted development during their daily communication at home (Skeat \& Roddam, 2019).

Parental engagement is a complex and multifaceted process in early speech therapy intervention. There is no single path that ensures engagement or disengagement. Parental engagement is frequently associated with parental factors such as their expectation, competence, and parenttherapist communication (King et al., 2021; Phoenix et al., 2018; Sugden et al., 2019). When these factors are adequately addressed, a positive outcome can be expected throughout the therapy session, and an active partnership or collaboration with the therapists throughout the intervention process (King et al., 2021; Melvin et al., 2021).

During the initial session of speech therapy intervention, parents need to be enlightened about their child's treatment to set a clear expectation between what they anticipate about the service and what is experienced in reality. Such consistency in expectation increased parental engagement (Davies et al., 2017; Phoenix et al., 2018). Nevertheless, mismatched expectations about the service provided by speech therapists often arise among the parents, subsequently affecting the parents' engagement (Klatte et al., 2019). Therefore, good communication between the practitioners and parents to establish expectations early in the intervention process is crucial to ensure ongoing engagement. Apart from that, effective communication and engagement can also enhance parents' knowledge and competence, subsequently empowering them to be more confident in applying the therapy at home with their children (Oono et al., 2018; Pickard et al., 2016; Stahmer et al., 2016). Furthermore, when practitioners create the necessary support to enhance parental competence and facilitate setting achievable goals, it will produce optimal parental engagement and assist parents in experiencing success (D’Arrigo et al., 2017).

In Malaysia, the data over the past decade from the Ministry of Health (MOH) showed an annual increase of 10 to 20 per cent in speech and language disorders among children. Untreated speech and language disorders often predispose to a high risk of behavioural, emotional, and psychosocial difficulties, as well as poorer mental health and reduced employment prospects (Bercow, 2018; Johnson et al., 
2010; Qi et al., 2020; Toseeb et al., 2020). In view of the rising cases and associated risks of untreated speech and language disorders in Malaysia, necessary strategies need to be established to assist these individuals. Hence, this study aimed to determine the critical factors affecting the roles of parents in the treatment of children's speech and language disorders.

\section{Theories and Conceptual Framework}

This study was guided by the Phoenix Theory of Attendance, Participation, and Engagement (PTAPE; Phoenix et al., 2019). The theory explains essential factors that affect parents' attendance, participation, and engagement in children's rehabilitation services. Additionally, the Engagement Capacity Model (Sieck et al., 2019) was also adopted to understand the capacity for patient engagement. The theories were then integrated to determine parental engagement in speech therapy.

The Phoenix Theory of Attendance, Participation, and Engagement. The Phoenix Theory of Attendance, Participation, and Engagement (PTAPE) was developed using a constructivist grounded theory study that applied constant comparison and theoretical sampling. The theory referred to the Family Stress Theory to define high-risk families, i.e. families of children with disabilities, in describing the types of services typically offered. Based on Figure 1, PTAPE comprehensively covers all the conditions that facilitate or inhibit families from attending, participating, and engaging in children's rehabilitation services (ABCDEF). Firstly, the theory outlines the factors from the perspective of (A) the family composition that includes adults and child factors, such as parents' age or the number of children in the family; (B) the health complexity that is about the physical and mental health of the family members; and (C) service complexity that represents the organisation and professionals involved. The ABC factors were the main barriers that can negatively impact parents' attendance, participation, and engagement. Under the PTAPE, (D) encompasses six factors, including logistics, values and beliefs, knowledge, feelings, skills, and relationship with the professionals. Next, (E) refers to the therapy process factors: expectations, motivation, communication, resources, and timing. These factors can either enhance or decrease attendance, participation, and engagement. Finally, (F) indicates the child's destination, which is for most parents to have a healthy and happy child.

The Engagement Capacity Model. The Engagement Capacity Model (ECM; Sieck et al., 2019) conceptualises the engagement capacity based on the Albert Bandura Social Cognitive Theory (Bandura, 1986). The theory describes the various ways that an individual acquires behaviour. It is believed that persons, environments, and behaviours are interconnected, influencing one another. A good understanding of this concept will assist the clinicians in patient engagement.

Based on Figure 2, The ECM revolves around the person-environment-behaviour concept that encompasses four elements. 


\section{A Family Composition A The family vehicle}

The family vehicle represents the number of adults who contribute to care, the parents' age and the number of children in the family

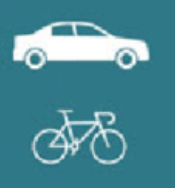

CO (4)
C Service Complexity The Road

The road represents the number of organizations and professionals.
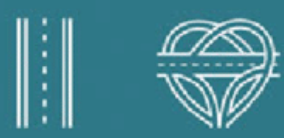

\section{B Health Complexity} The Working Condition

The working condition represents accumulated child, sibling and parent physical and mental health
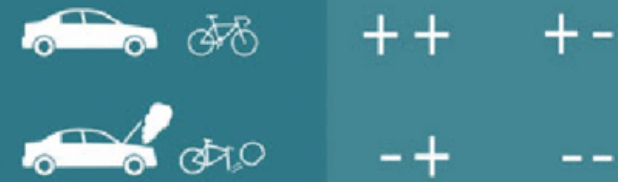
$--$
D The Process of Attendance, Participation and Engagement The Parent Gears

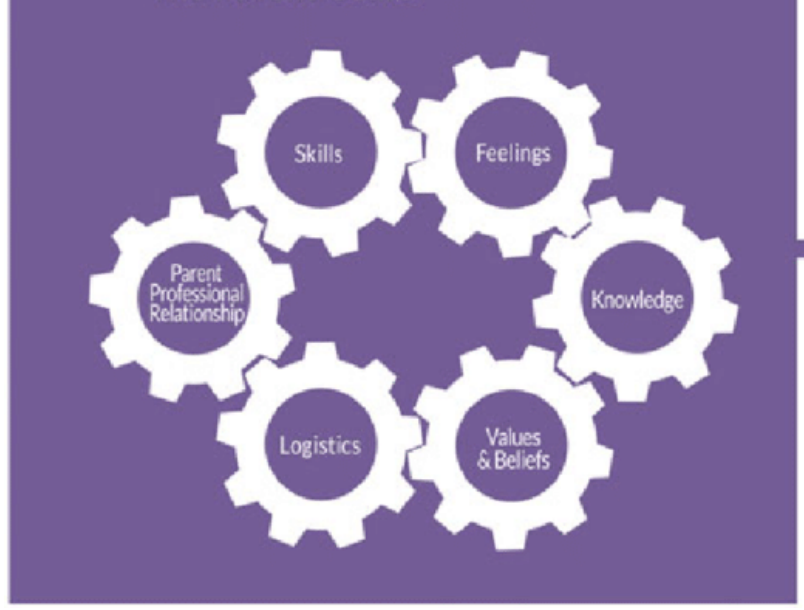

Figure 1. The Phoenix Theory of Attendance, Participation and Engagement (Phoenix et al., 2019) 
The first concept, self-efficacy, is the individuals' belief in their capability to perform a behaviour. The model believes that improvement in self-efficacy leads to better adherence to treatment procedures. The second element is resources, including financial resources, access-related resources, and person-related resources that support the individuals to participate in treatment. The model explains that patients who lack resources are less likely to engage fully in their treatment. The third element is willingness. It is related to the patient's preparedness to proceed or take action. For example, a patient's ability to engage may be inhibited by his unwillingness to share information. Finally, all the three elements mentioned above are supported by patients' knowledge, understanding, and skills, collectively refer as capabilities in this model that enable them to act.

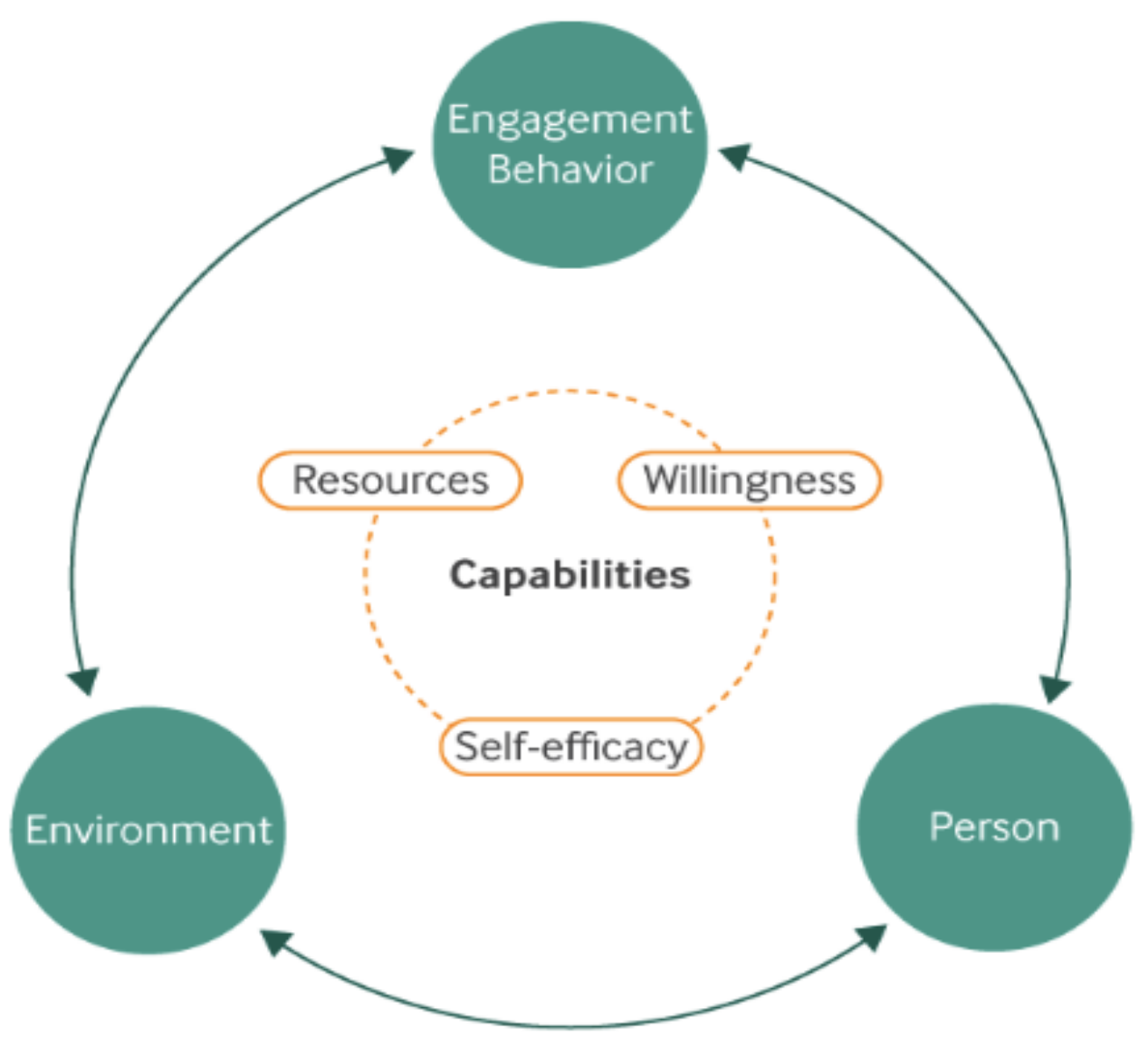

Figure 2. The Engagement Capacity Model (Sieck et al., 2019) 
Integration of Theories. There was no single theory that can explain the predictors and mediators of parental engagement. Therefore, a theoretical framework was developed in this study. Figure 3 illustrates the theoretical framework for the study that attempts to explore parental engagement in speech therapy for children with speech and language disorders. The framework incorporates the differences and similarities between the PTAPE and the ECM based on the current literature findings of the theory and model mentioned above.

In the ECM, behaviours such as engagement are influenced by two elements, namely person and environment. Hence, any changes in these elements may change the degree of engagement. It is also applicable to the features in the PTAPE. In this study, child-related factors under (A) Family composition (the child's sibling or the number of children in the family)

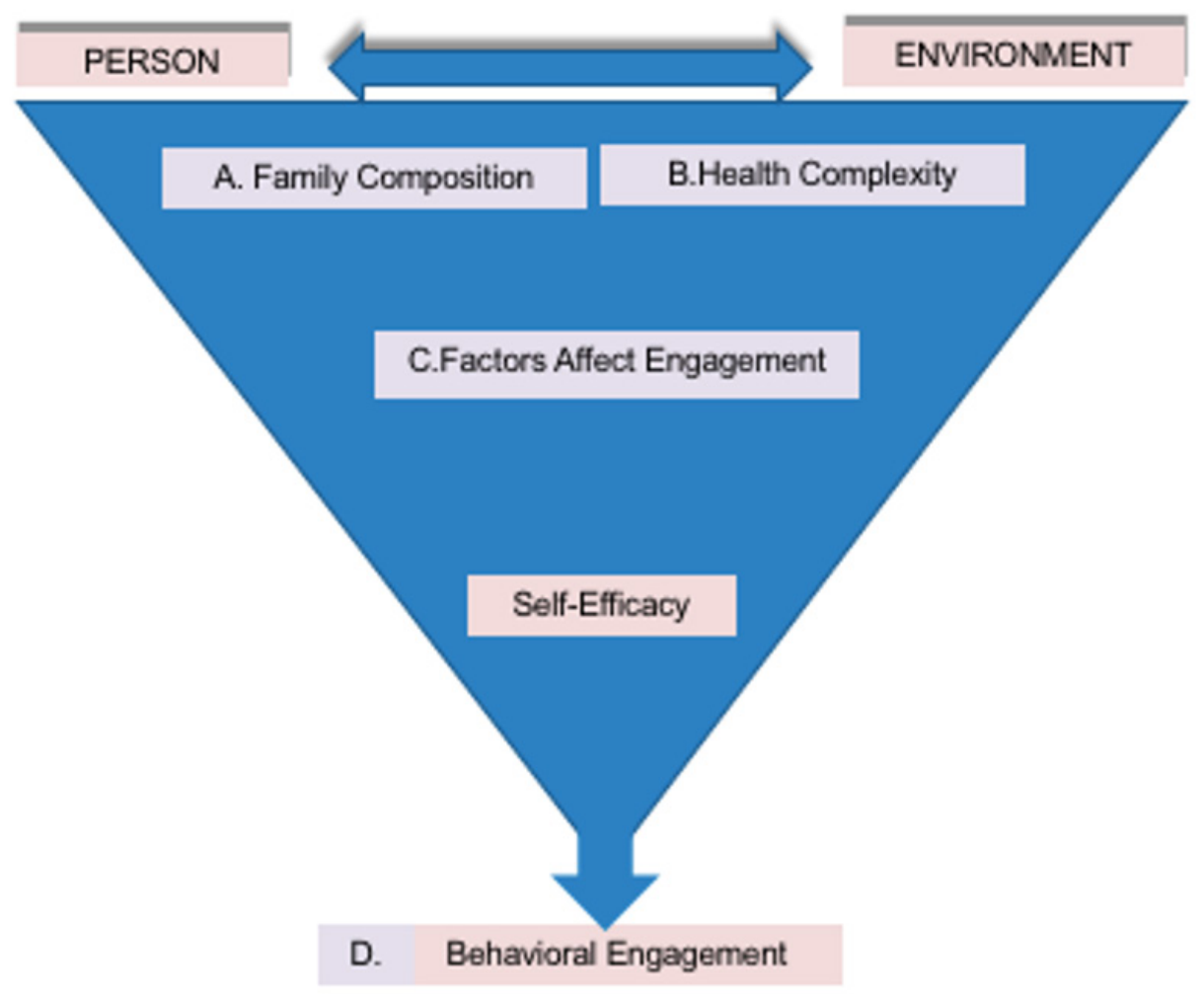

The Phoenix Theory of Parent Aftendance, Participation and Engagement

The Engagement Capacity Model

Figure 3. The theoretical framework for the study 
and (B) Health complexity (the child's medical diagnosis) appeared to be essential antecedent variables that affected parental engagement. Armed with this information, clinicians can categorise parents into different groups and customise the strategies based on the level of parental engagement. For this study, only two factors in the group of service complexity (C) were selected, namely: parental expectation for speech therapy and parent-therapist communication during therapy. Both factors are highly associated with the ability to facilitate or limit parental engagement. In addition, the component of self-efficacy in the ECM indicates whether the parents perceived that they are competent in speech therapy. Finally, all the factors are presumed to be related to one another. Therefore, any changes in one element can lead to a decreased or increased level of Behavioural
Engagement (D), i.e. parental engagement during speech therapy.

Conceptual Framework. The conceptual framework in this study was constructed based on the PTAPE (Phoenix etal., 2019) and the ECM (Sieck et al., 2019). As illustrated in Figure 4, expectation, communication, and competence were assumed to contribute to parental engagement directly. Additionally, competence is expected to be mediating the expectation and communication. Considering the direct effect of competence on engagement, it can play a mediating role between the predictors and parental engagement. Finally, the difference in the number of children in the family and the severity of the child's medical condition was also postulated to result in different levels of parental engagement.

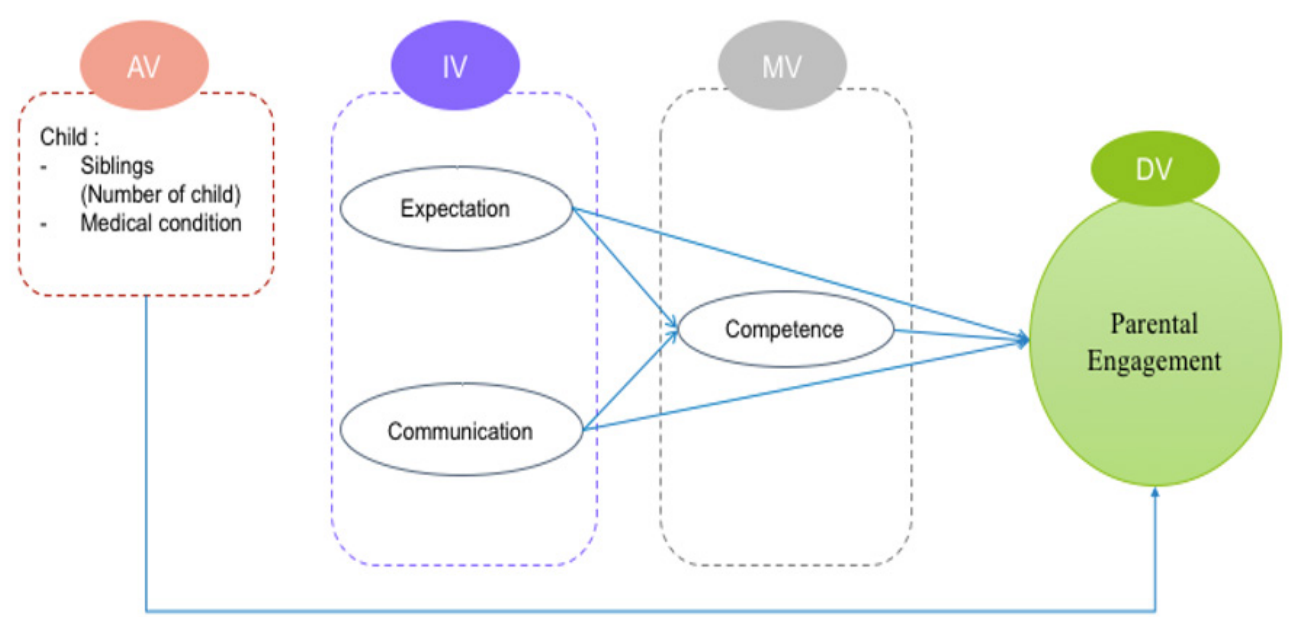

Figure 4. Conceptual framework for the study 
Based on the conceptual framework, the study objectives include:

Objective 1: To compare the parental engagement between parents with one child and more than one child in the family. Ha1: There is a significant difference in parental engagement between parents with one child and more than one child in the family.

Objective 2: To compare the parental engagement between parents with a child without a medical condition and parents with a child with a medical condition. Ha2: There is a significant difference in parental engagement between parents with a child without a medical condition and parents with a child with a medical condition.

Objective 3: To examine the mediating effects of competence on expectation, communication, and parental engagement in speech therapy. Ha3: Competence mediates the relationship between expectation and parental engagement in speech therapy. Ha4: Competence mediates the relationship between communication and parental engagement in speech therapy.

Table 1

Frequency distribution of parents' background information $(N=389)$

\begin{tabular}{|c|c|c|}
\hline Variables & Freq. & Percent \\
\hline \multicolumn{3}{|l|}{ Parents } \\
\hline Father & 65 & 17 \\
\hline Mother & 319 & 82 \\
\hline $\begin{array}{l}\text { Others } \\
\text { (individual who have legal rights on the child e.g. step parent) }\end{array}$ & 5 & 1 \\
\hline \multicolumn{3}{|l|}{ Age } \\
\hline 17 years and below & 13 & 3 \\
\hline $18-29$ years old & 47 & 12 \\
\hline $30-49$ years old & 327 & 84 \\
\hline 50 years and above & 2 & 1 \\
\hline \multicolumn{3}{|l|}{ Race } \\
\hline Malay & 363 & 93 \\
\hline Chinese & 19 & 5 \\
\hline Indian & 3 & 1 \\
\hline Others & 4 & 1 \\
\hline \multicolumn{3}{|l|}{ Academic qualification } \\
\hline High School & 100 & 26 \\
\hline Certificate & 18 & 5 \\
\hline Diploma & 112 & 29 \\
\hline Degree & 144 & 37 \\
\hline Master / PhD & 15 & 4 \\
\hline
\end{tabular}


Table 1 (Continued)

\begin{tabular}{lcc}
\hline Variables & Freq. & Percent \\
\hline Household Income & & \\
Less than RM1005 & 29 & 8 \\
RM1006-3955 & 152 & 39 \\
RM3956-12235 & 197 & 51 \\
More than RM12235 & 11 & 3 \\
\hline
\end{tabular}

\section{METHOD}

\section{Participants}

This study recruited 389 parents as participants. They were either mother or father with a child below 18 years old attending speech therapy sessions in government hospitals. Table 1 displays the sociodemographic characteristics of the participants. Most of them were mothers $(82 \%)$ and Malays (93\%). Every four out of five $(84 \%)$ respondents were between 30 to 49 years old. According to the World Bank Classification of income levels, more than half (51\%) earned more than RM 3956 monthly (upper-middle-income group). In comparison, $36 \%$ were categorised under the lower-middle-income group (RM 10063955).

Table 2 shows the background information of the participants' children. Most of the children were males (72\%). More than half $(57 \%)$ of the children were between two to four years old, followed by five to seven-year-old children (33\%). Most children have more than one sibling (83\%), while the rest $(17 \%)$ were the only child. Less than half (41\%) of the children did not have any medical conditions. In comparison, the rest had either Autism (24.9\%), Downs
Syndrome (7\%), Hearing Impairment (4\%), Cerebral Palsy (4\%), Cleft Lip and Palate (2\%), ADHD (2\%) and other medical conditions $(16 \%)$.

\section{Procedures}

This study involved a survey using a selfadministered questionnaire. First, the original questionnaire in the English language was translated into Malay, the national language of Malaysia. The Malay version of the questionnaire would help the respondents to understand the questions better. Then, the researcher did back-translation of the original English questionnaire into Malay, followed by translating Malay to English by another bilingual professional in the related field without referring to the original text (Shigenobu, 2007). Finally, all the items in the instrument were evaluated and validated by a bilingual psychologist from the Ministry of Health. Prior to data collection, a pilot study was conducted among 30 participants. The items in the questionnaire were modified based on their comments and suggestions. This study received ethics approval from the Medical Research Ethics Committee of the Ministry of Health Malaysia and permission from 
the hospital directors and Clinical Research around 30-40 minutes to complete. All the Centre of all study sites. The parents were participants were given a free e-book as a given the option to fill in the online version token of appreciation once they returned the or hard copy of the questionnaire that took completed questionnaires.

Table 2

Frequency distribution of childs' background information $(N=389)$

\begin{tabular}{lcc}
\hline Variables & Freq. & Percent \\
\hline Gender & 280 & 72 \\
$\quad$ Male & 109 & 28 \\
Female & & \\
Age & 10 & 3 \\
Below 2 years old & 223 & 57 \\
2-4 years old & 127 & 33 \\
5-7 years old & 29 & 8 \\
More than 7 years old & & \\
Siblings & 65 & 17 \\
No sibling & 165 & 42 \\
1-2 siblings & 134 & 34 \\
3-4 siblings & 25 & 6 \\
More than 4 siblings & & \\
Medical Diagnosis & 158 & 41 \\
No medical condition & 97 & 25 \\
Autism & 16 & 4 \\
Hearing Impairment & 28 & 7 \\
Downs Syndrome & 14 & 4 \\
Cerebral Palsy & 7 & 2 \\
Cleft Lip \& Palate & 7 & 2 \\
ADHD & 62 & 16 \\
Others & & \\
\hline
\end{tabular}

\section{Measures}

Standardised instruments in questionnaires were used to assess respondents, demographic background (parent and child), parents' competence, communication, expectation, and parental engagement. 
Perceived Competence Scale. The competence of the parents was assessed using the Perceived Competence Scale (PCS). It was specially adapted to fit the relevant domain in this study. The PCS examined the perceived competence among the participants in terms of their ability to engage of follow through on some commitment. For example, the individuals' adherence to healthier behaviours or their participation in activities related to child development. PCS is one of the instruments with a high level of face validity for assessing the constructs of competence. It consists of four items on a 7-point Likert scale. Some examples of the items are "I feel confident in my ability to learn this material" and "I can achieve my goals in this course". The alpha measure of internal consistency for the perceived competence items in the previous study was above 0.80 , thus indicating that the scale had good reliability (Williams et al., 1998).

Therapist-Parent Communication Questionnaire. In this study, communication was measured using the Dimensions of Therapist-Parent Communication Questionnaire. The 15-item questionnaire was created based on the Parent Satisfaction with Children's Medical Care Questionnaire developed by Lewis et al. (1986) and The Medical Interview Satisfaction Scale developed by Wolf et al. (1978). The scale was rephrased based on the evaluation of the clinicians' behaviour. It uses an eightpoint Likert scale between 1-“absolutely do not agree" to 8-"absolutely agree". The items are categorised into three dimensions of communication using varimax rotation: caring (6 items), interest (5 items), and collaboration (4 items) with internal reliability alpha-value of $0.88,0.79$, and 0.83 , respectively. Some examples of items are "The therapist cares about us" under the dimension of caring; "The therapist shows interest in our life at home" under the dimension of interest; and "The therapist decides without us and gives us his decision" under the dimension of collaboration (Bachner et al., 2006).

Parental Expectation Scale. Next, the parental expectation for therapy was measured using an adapted survey of the Expectations for Speech-Language Therapy developed by Macintyre (2018). The survey included questions focused on investigating parents' expectations of speech-language therapy in New Zealand based on previous research (Auert et al., 2012; Carroll, 2010; Lyons et al., 2010). The validation of the items in the survey was done through expert review. Firstly, the questions were discussed between the researcher and the professor in the related field. Then, ten practising Speech Therapists reviewed the questionnaire to check if the items were appropriate and relevant. Finally, the survey was piloted, and any changes were made accordingly. The questionnaire consists of four items on a seven-point Likert scale. Some examples of the items are "I expected to be involved in my child's speech-language therapy" and "I expected to be given home practice to do with my child". 
Parent Home-Programme Compliance Questionnaire. Lastly, parental engagement in speech therapy was assessed using the Parent Home-Programme Compliance Questionnaire. It consists of four items that assess their comfort, knowledge, and ability to carry out the home programme. It is measured using a five-point Likert scale, ranging from 1-strongly disagree to 5-strongly agree. Some examples of the items are "I felt that I was skilful in carrying the home programme" and "I was able to carry out the programme as often as expected."

The scale was validated in a study that evaluated community professionals' compliance with consultants, recommendations for developmentally disabled children (Cadman et al., 1986). In that study, the scale was 0.7 using weighted kappa statistics, thus indicating a good test-retest reliability. In addition, the agreement between the client's selfreporting score on the questionnaire and independent observation was calculated. The weighted kappa was greater than 0.9, showing excellent agreement. Hence, validity was supported (Law \& King, 1993).

\section{Data Analysis}

Data entry and data analysis were performed using SPSS and SMART-PLS. Data analysis started with data cleaning, followed by descriptive analysis, bivariate analysis, and PLS-SEM analysis. In the evaluation of PLS-SEM, two stages were involved. Stage one involved the reflective model evaluation or formative model evaluation. The process continued with evaluating the structural model in stage two after the measurement quality was supported (Hair et al., 2017) by testing the proposed hypotheses and addressing the relationships between the latent variables.

\section{RESULTS AND DISCUSSIONS}

Comparison Between Parents with One Child and More Than One Child in the Family

Independent samples t-test analysis was conducted to compare the differences in parental engagement between parents with one child and more than one child in the family. The results revealed significant mean difference $[\mathrm{t}(387)=3.321, \mathrm{p}=0.001]$. The mean parental engagement score for parents with one child $(\mathrm{M}=4.042, \mathrm{SD}=$ 0.650) was slightly higher than those with more than one child in the family $(\mathrm{M}=$ $3.746, \mathrm{SD}=0.657)$. The effect size $(\mathrm{d})$ was 0.451 , indicating a small effect. The results supported the conclusion that the parental engagement between one child and more than one child in the family was significantly different. Thus, hypothesis one (Ha1) was accepted. Based on the findings, parents with one child in the family had a higher engagement than parents with more than one child. This finding was comparable with other studies that found families with more than one child were associated with lower program enrollment and engagement (Eisner \& Meidert, 2011). The difference could be attributed to having multiple children placing additional strains on parents' time, 
energy, and finances (McConnell et al., 2014).

\section{Comparison Between Parents with Child without Medical Condition and Parents with Child with Medical Conditions}

Independent samples t-test analysis was employed to test the differences in parental engagement between parents with a child without medical conditions and parents with a child with medical conditions. There was a significant mean difference [t $(387)=2.390, \mathrm{p}=0.017]$ between the parental engagement of those with a child without medical condition $(\mathrm{M}=3.892$, SD $=0.680)$ and with medical condition $(\mathrm{M}=$ $3.729, \mathrm{SD}=0.647)$. However, the effect size $(\mathrm{d}=0.247)$ was small, indicating a small effect. The results concluded that the parental engagement between parents with a child without a medical condition and parents with a child with a medical condition was significantly different. Thus, hypothesis two (Ha2) was accepted. Parents who have a child without a medical condition showed higher engagement than parents whose child had a medical condition. This result was aligned with previous works by Haine-Schlagel and Walsh (2015) and Mauricio et al. (2014), whereby families whose children had more severe symptoms were less likely to engage in therapy. On the contrary, some other studies reported that the child's symptom severity predicted greater engagement, likely due to a greater perceived need for treatment (Baydar et al., 2003; Garbacz et al., 2017).

\section{Mediation of Parental Engagement}

In order to analyse the indirect effect, the direct effect must be established first. The PLS-SEM path coefficient showed the results below: Competence $(\beta=.373$, $\mathrm{p}<0.01)$, Communication $(\beta=.283, \mathrm{p}<0.01)$, and Expectation $(\beta=.168, \mathrm{p}<0.01)$. Thus, all showed a significant direct contribution towards parental engagement. Table 3 shows the results of the mediation analysis. The bootstrapping procedure showed the significant indirect effects for $\mathrm{Ha} 3(\beta=$ $0.194)$ and Ha4 $(\beta=0.068)$ with $\mathrm{t}$-values of 6.062 and 3.480 respectively. The $95 \%$ confidence intervals of $[\mathrm{LL}=0.134, \mathrm{UL}=$ $0.260]$ and $[\mathrm{LL}=0.032, \mathrm{UL}=0.109] \mathrm{did}$ not include the value zero in between, thus indicating a mediation role of both variables (Preacher \& Hayes, 2008). The results concluded that all the mediation effects were statistically significant. Hence hypothesis 3 (Ha3) and hypothesis 4 (Ha4) were accepted.

Based on the findings, Ha 3 was accepted, thus indicating that competence partially mediated the relationship between expectation and parental engagement in the child's speech therapy. In other words, parents with less expectation are likely to have lower competence, leading to lower engagement. Thus, even though the expectation is necessary, parents' competence also plays a significant role in determining the outcome of parental engagement. The Social Cognitive Theory (Bandura, 1986) also reported that parents with high self-efficacy strongly believe in their capabilities to achieve their 
Table 3

Hypothesis testing on mediation analysis

\begin{tabular}{|c|c|c|c|c|c|c|c|}
\hline \multirow[t]{2}{*}{ Hypotheses } & \multirow[t]{2}{*}{ Relationship } & \multirow[t]{2}{*}{$\begin{array}{l}\text { Std. } \\
\text { Beta }\end{array}$} & \multirow[t]{2}{*}{$\begin{array}{l}\text { Std. } \\
\text { Error }\end{array}$} & \multirow[t]{2}{*}{ t-value } & \multicolumn{2}{|c|}{$\begin{array}{c}\text { Confidence } \\
\text { Interval (BC) }\end{array}$} & \multirow[t]{2}{*}{ Decision } \\
\hline & & & & & LL & UL & \\
\hline На3 & $\begin{array}{c}\text { Expectation } \\
<\text { Competence }> \\
\text { Engagement }\end{array}$ & 0.194 & 0.032 & $6.062 * *$ & 0.134 & 0.260 & Accepted \\
\hline Ha4 & $\begin{array}{c}\text { Communication } \\
<\text { Competence }> \\
\text { Engagement }\end{array}$ & 0.068 & 0.020 & $3.480 * *$ & 0.032 & 0.109 & Accepted \\
\hline
\end{tabular}

Note. $* * \mathrm{p}<0.001$

expectations. They are also more motivated to complete tasks as they are more adaptive to challenging situations. Similarly, Arellano et al. (2019) examined the association between mothers' sense of competence and future expectations. They reported that higher maternal expectations of their child's future were associated with a more positive parenting sense of competence. Subsequently, this was linked with an increased engagement in their development activities.

Finally, Ha4 was also accepted based on the findings whereby parental competence partially mediated the relationship between communication and parental engagement in speech therapy for children with speech and language disorders. As a result, communication affected parental engagement both directly and indirectly through competence. Very often, parents who maintained good communication with their clinicians displayed a higher level of parental engagement. Furthermore, good parent-clinician communication also improved parental competence and subsequently fostered better parental engagement. This finding was also supported by past studies in which positive communication with service providers led to a higher competence (Davies et al., 2017) that subsequently increased parental engagement in the intervention (Freckmann et al., 2017).

Additionally, Melvin et al. (2019) also recommended that speech therapists support parents by building a trusting relationship and working closely with them during intervention sessions. Such rapport can improve parental competence to make them more engaged in early intervention for speech pathology. Such findings were justifiable because parents are often responsible for initiating and practising at home. Furthermore, parents had higher competence levels when they had a strong working relationship through good communication with the clinicians (Ebert, 2018). To improve the confidence and competence of parents in guiding their 
child's development, therapists should discuss the issues that affect parents' attitudes and feelings towards therapy, and offer adequate support and guidance to them.

\section{CONCLUSION}

Speech and language disorders are one of the leading development concerns in childhood. Timely speech therapy intervention can produce better outcomes for the children. However, it can be hindered by poor parental engagement in practising the intervention strategies at home. To increase parental engagement in these programmes, we need to understand the crucial role of parental engagement better. Hence, this study contributed to the literature gaps by providing empirical evidence on the association between expectation, communication, competence, and parental engagement in speech therapy for children with speech and language disorders. Moreover, the quantitative method in this study enabled the researcher to produce objective findings on the associated factors of parental engagement.

Additionally, the study findings also led to significant theoretical contributions. Based on the PTAPE (Phoenix et al., 2019), competence, expectation, and communication are among the factors that facilitate or inhibit the process of parental engagement. If these factors are limited, parents may attend therapy inconsistently or entirely withdraw from the therapy. The current findings showed that expectation, communication, and competence significantly contribute to parental engagement. These findings were in line with PTAPE (Phoenix et al., 2019).

Meanwhile, the Engagement Capacity Model (Sieck et al., 2019) focuses more on patients capabilities, self-efficacy, or competence. These elements need to be enhanced to improve the clinicians' ability in helping the patients to engage. The present study results highlighted that parental competence mediated the relationship between communication, expectation, and parental engagement. Moreover, competence exerted the biggest influence on parental engagement compared to other factors, as highlighted by the Engagement Capacity Model (Sieck et al., 2019).

The current policy in speech therapy services centres on the child with speech and language disorder but often neglects significant others such as parents and family members. Hence, this study highlighted to policymakers the importance of prioritising strategies on improving parental competence, expectation, and parenttherapist communication. These features can ensure necessary actions for highly parental engagement in speech therapy.

Lastly, it is vital to customise treatment programmes attuned to each parent and family to achieve optimal parental engagement. Study findings have highlighted the importance of identifying parents at risk of low engagement for therapy, including those with more than one child in the family and those whose child has a more severe medical condition. Thus, to increase the engagement in these groups, 
intervention should emphasise providing adequate information on the importance and credibility of speech therapy to establish an acceptable expectation for the rate and magnitude of their child's improvement.

Overall, this study identified the critical factors that affected parental engagement. Parental engagement in speech therapy for the paediatric population is a complex interaction between multiple factors, namely competence, expectation, and communication. By addressing these contributing factors of parental engagement, researchers, policymakers, and clinicians can better understand, plan, develop, and practise the most effective treatment strategies for children and family members involved in speech therapy.

\section{ACKNOWLEDGEMENTS}

The authors would like to acknowledge the funding from the Ministry of Health and support from all hospital staff, parents and families. Without their cooperation and participation, this study could not have been completed.

\section{REFERENCES}

American Speech-Language-Hearing Association. (2008). Roles and responsibilities of speechlanguage pathologists in early intervention: Guidelines. Early communication intervention. https://doi.org/10.1044/policy.GL2008-00290

Arellano, A., Denne, L. D., Hastings, R. P., \& Hughes, J. C. (2019). Parenting sense of competence in mothers of children with autism: Associations with parental expectations and levels of family support needs. Journal of Intellectual and
Developmental Disability, 44(2), 212-218. https://doi.org/10.3109/13668250.2017.1350838

Auert, E. J., Trembath, D., Arciuli, J., \& Thomas, D. (2012). Parents' expectations, awareness, and experiences of accessing evidence-based speech-language pathology services for their children with autism. International Journal of Speech-Language Pathology, 14(2), 109-118. https://doi.org/10.3109/17549507.2011.652673

Bachner, Y. G., Carmel, S., Lubetzky, H., Heiman, N., \& Galil, A. (2006). Parent-therapist communication and satisfaction with the services of a child development center: A comparison between Israeli parents - Jews and Bedouins. Health Communication, 19(3), 221-229. https:// doi.org/10.1207/s15327027hc1903_4

Bandura, A. (1986). Social foundations of thought and action: A social cognitive theory. PrenticeHall, Inc.

Baydar, N., Reid, M. J., \& Webster-Stratton, C. (2003). The role of mental health factors and program engagement in the effectiveness of a preventive parenting program for head start mothers. Child Development, 74(5), 1433-1453. https://doi.org/10.1111/1467-8624.00616

Bercow. (2018). Bercow : Ten years on. Royal College of Speech and Language Therapists, March, 1-6. https://www.bercow10yearson.com/wpcontent/uploads/2018/04/Bercow-Ten-Years-OnSummary-Report-.pdf

Cadman, D., Rosenbaum, P., Walter, S., \& McNamee, J. (1986). Community professionals' compliance with consultants' recommendations for developmentally disabled children. Journal of Developmental and Behavioral Pediatrics, 7(1), 21-26. https://doi.org/10.1097/00004703198602000-00004

Carroll, C. (2010). It's not everyday that parents get a chance to talk like this: Exploring parents' 
perceptions and expectations of speech-language pathology services for children with intellectual disability. International Journal of SpeechLanguage Pathology, 12(4), 352-361. https:// doi.org/10.3109/17549500903312107

D’Arrigo, R., Ziviani, J., Poulsen, A. A., Copley, J., \& King, G. (2017). Child and parent engagement in therapy: What is the key? Australian Occupational Therapy Journal, 64(4), 340-343. https://doi.org/10.1111/1440-1630.12279

Davies, K. E., Marshall, J., Brown, L. J. E., \& Goldbart, J. (2017). Co-working: Parents' conception of roles in supporting their children's speech and language development. Child Language Teaching and Therapy, 33(2), 171185. https://doi.org/10.1177/0265659016671169

Division for Early Childhood. (2014). DEC recommended practices in early intervention/ early childhood special education. https://www. dec-sped.org/dec-recommended-practices

Ebert, K. D. (2018). Parent perspectives on the clinician-client relationship in speech-language treatment for children. Journal of Communication Disorders, 73(March), 25-33. https://doi. org/10.1016/j.jcomdis.2018.03.005

Eisner, M., \& Meidert, U. (2011). Stages of parental engagement in a universal parent training program. Journal of Primary Prevention, 32(2), 83-93. https://doi.org/10.1007/s10935-0110238-8

Freckmann, A., Hines, M., \& Lincoln, M. (2017). Clinicians' perspectives of therapeutic alliance in face-to-face and telepractice speech-language pathology sessions. International Journal of Speech-Language Pathology, 19(3), 287-296. https://doi.org/10.1080/17549507.2017.1292547

Garbacz, S. A., Mcintyre, L. L., \& Santiago, R. T. (2017). Family involvement and parent-teacher relationships for students with autism spectrum disorders. School Psychology Quarterly, 31(4), 478-490. https://doi.org/10.1037/spq0000157

Haine-Schlagel, R., \& Walsh, N. E. (2015). A review of parent participation engagement in child and family mental health treatment. Clinical Child and Family Psychology Review, 18(2), 133-150. https://doi.org/10.1007/s10567-015-0182-x

Hair, J. F., Hult, J. G. T. M., Ringle, C. M., \& Sarstedt, M. (2017). A Primer on Partial Least Squares Structural Equation Modeling (PLS-SEM). Journal of Chemical Information and Modeling, 8(9), 1-58.

Johnson, C. J., Beitchman, J. H., \& Brownlie, E. B. (2010). Twenty-year follow-up of children with and without speech-language impairments: Family, educational, occupational, and quality of life outcomes. American Journal of SpeechLanguage Pathology, 19(1), 51-65. https:/doi. org/10.1044/1058-0360(2009/08-0083)

King, G., Chiarello, L. A., Ideishi, R., Ziviani, J., Phoenix, M., McLarnon, M. J. W., Pinto, M., Thompson, L., \& Smart, E. (2021). The complexities and synergies of engagement: an ethnographic study of engagement in outpatient pediatric rehabilitation sessions. Disability and Rehabilitation, 43(16), 2353-2365. https://doi.or g/10.1080/09638288.2019.1700562

King, G., Chiarello, L. A., McLarnon, M. J. W., Ziviani, J., Pinto, M., Wright, F. V., \& Phoenix, M. (2021). A measure of parent engagement: Plan appropriateness, partnering, and positive outcome expectancy in pediatric rehabilitation sessions. Disability and Rehabilitation, 1-10. https://doi.org/10.1080/09638288.2020.1864036

Klatte, I. S., Harding, S., \& Roulstone, S. (2019). Speech and language therapists' views on parents' engagement in Parent-Child Interaction Therapy (PCIT). International Journal of Language \& Communication Disorders, 54(4), 553-564. https://doi.org/10.1111/1460-6984.12459 
Law, M., \& King, G. (1993). Parent compliance with therapeutic interventions for children with cerebral palsy. Developmental Medicine \& Child Neurology, 35(11), 983-990. https://doi. org/10.1111/j.1469-8749.1993.tb11580.x

Lewis, C. C., Scott, D. E., Pantell, R. H., \& Wolf, M. H. (1986). Parent satisfaction with children's medical care. Medical Care, 24(3), 209-215. https://doi.org/10.1097/00005650-19860300000003

Lyons, R., O’Malley, M. P., O’Connor, P., \& Monaghan, U. (2010). "It's just so lovely to hear him talking": Exploring the early-intervention expectations and experiences of parents. Child Language Teaching and Therapy, 26(1), 61-76. https://doi.org/10.1177/0265659009349975

Macintyre, S. (2018). Parents' expectations and experiences of child-focused speech-language therapy in New Zealand (Issue August) [Master's thesis, University of Canterbury]. http://doi. org/10.26021/8155

Mauricio, A. M., Tein, J. Y., Gonzales, N. A., Millsap, R. E., Dumka, L. E., \& Berkel, C. (2014). Participation patterns among Mexican-American parents enrolled in a universal intervention and their association with child externalizing outcomes. American Journal of Community Psychology, 54(3-4), 370-383. https://doi. org/10.1007/s10464-014-9680-0

McConnell, D., Savage, A., \& Breitkreuz, R. (2014). Resilience in families raising children with disabilities and behavior problems. Research in Developmental Disabilities, 35(4), 833-848. https://doi.org/10.1016/j.ridd.2014.01.015

Melvin, K., Meyer, C., \& Scarinci, N. (2019). What does "engagement" mean in early speech pathology intervention? A qualitative systematised review. Disability and Rehabilitation, 42(18), 26652678. https://doi.org/10.1080/09638288.2018. 1563640
Melvin, K., Meyer, C., \& Scarinci, N. (2021). Exploring the complexity of how families are engaged in early speech-language pathology intervention using video-reflexive ethnography. International Journal of Language \& Communication Disorders, 56(2), 360-373. https://doi.org/10.1111/1460-6984.12609

Oono, I. P., Honey, E. J., \& McConachie, H. (2018). Parent-mediated early intervention for young children with autism spectrum disorders (ASD). Cochrane Database of Systematic Reviews, 10(4), 1-12. https://doi.org/10.1002/14651858. CD009774

Phoenix, M., Jack, S. M., Rosenbaum, P. L., \& Missiuna, C. (2018). A grounded theory of parents' attendance, participation and engagement in children's developmental rehabilitation services: Part 2. The journey to child health and happiness. Disability and Rehabilitation, 42(15), 1464-5165. https://doi.org/10.1080/09638288.2 018.1555618

Phoenix, M., Jack, S. M., Rosenbaum, P. L., \& Missiuna, C. (2019). Parents' attendance, participation and engagement in children's developmental rehabilitation services: Part 1. Contextualizing the journey to child health and happiness. Disability and Rehabilitation, 42(15), 1464-5165. https://doi.org/10.1080/09638288.2 018.1555618

Pickard, K. E., Kilgore, A. N., \& Ingersoll, B. R. (2016). Using community partnerships to better understand the barriers to using an evidence-based, parent-mediated intervention for autism spectrum disorder in a medicaid system. American Journal of Community Psychology, 57(3-4), 391-403. https://doi.org/10.1002/ ajcp. 12050

Preacher, K. J., \& Hayes, A. F. (2008). Asymptotic and resampling strategies for assessing and comparing indirect effects in multiple mediator 
models. Behavior Research Methods, 40(3), 879-891. https://doi.org/10.3758/BRM.40.3.879

Qi, C. H., Van Horn, M. L., Selig, J. P., \& Kaiser, A. P. (2020). Relations between language skills and problem behaviour in preschool children. Early Child Development and Care, 190(16), 2493-2504. https://doi.org/10.1080/03004430. 2019.1588264

Shigenobu, T. (2007). Evaluation and usability of back translation for intercultural communication. In Lecture Notes in Computer Science (including subseries Lecture Notes in Artificial Intelligence and Lecture Notes in Bioinformatics): Vol. 4560 LNCS (Issue Part 2, pp. 259-265). https://doi. org/10.1007/978-3-540-73289-1_31

Sieck, C. J., Walker, D. M., Retchin, S., \& McAlearney, A. S. (2019). The patient engagement capacity model: What factors determine a patient's ability to engage? NEJM Catalyst, 1-10. https://catalyst. nejm.org/patient-engagement-capacity-model/

Skeat, J., \& Roddam, H. (2019). What do parents think about their involvement in speech-language pathology intervention? A qualitative critically appraised topic. Evidence-Based Communication Assessment and Intervention, 13(1-2), 15-31. https://doi.org/10.1080/17489539.2019.1600293

Stahmer, A. C., Brookman-Frazee, L., Rieth, S. R., Stoner, J. T., Feder, J. D., Searcy, K., \& Wang, T. (2016). Parent perceptions of an adapted evidence-based practice for toddlers with autism in a community setting. Autism, 21(2), 217-230. https://doi.org/10.1177/1362361316637580
Sugden, E., Munro, N., Trivette, C. M., Baker, E., \& Williams, A. L. (2019). Parents' experiences of completing home practice for speech sound disorders. Journal of Early Intervention, 41(2), 159-181. https://doi. org/10.1177/1053815119828409

Toseeb, U., Gibson, J. L., Newbury, D. F., Orlik, W., Durkin, K., Pickles, A., \& Conti-Ramsden, G. (2020). Play and prosociality are associated with fewer externalizing problems in children with developmental language disorder: The role of early language and communication environment. International Journal of Language \& Communication Disorders, 55(4), 583-602. https://doi.org/10.1111/1460-6984.12541

Williams, G. C., Freedman, Z.R., \& Deci, E. L. (1998). Perceived competence scales. Diabetes Care, 21(1996), 3. https://selfdeterminationtheory.org/ perceived-competence-scales/

Wolf, M. H., Putnam, S. M., James, S. A., \& Stiles, W. B. (1978). The medical interview satisfaction scale: Development of a scale to measure patient perceptions of physician behavior. Journal of Behavioral Medicine, 1(4), 391-401. https://doi. org/10.1007/BF00846695 
